\title{
Findings from the first public COVID-19 temporary test centre in Hong Kong
}

\author{
Will LH Leung *, Ellen LM Yu, SC Wong, M Leung, Larry LY Lee, KL Chung, Vincent CC Cheng
}

\section{A B S T R A C T}

Introduction: The Hospital Authority of Hong Kong Special Administrative Region established a coronavirus disease 2019 (COVID-19) temporary test centre at the AsiaWorld-Expo from March 2020 to April 2020, which allowed high-risk individuals to undergo early assessment of potential severe acute respiratory syndrome coronavirus 2 (SARS-CoV-2) infection. This study reviewed the characteristics and outcomes of individuals who attended the centre for COVID-19 testing.

Methods: This retrospective cross-sectional study collected epidemiological and clinical data. The primary outcome was a positive or negative SARS-CoV-2 test result, according to reverse transcription polymerase chain reaction analyses of pooled nasopharyngeal and throat swabs collected at the centre. The relationships of clinical characteristics with SARS-CoV-2 positive test results were assessed by multivariable binary logistic regression.

Results: Of 1258 attendees included in the analysis, 86 individuals tested positive for SARS-CoV-2 infection (positivity rate $=6.84 \%$; 95\% confidence interval $[\mathrm{CI}]=5.57 \%-8.37 \%)$. Of these 86 individuals, $40(46.5 \%)$ were aged 15 to 24 years and 81 (94.2\%) had a history of recent travel. Symptoms were reported by $86.0 \%$ and $96.3 \%$ of individuals with positive and negative test results, respectively. The clinical characteristics most strongly associated with
This article was published on $1 \mathrm{Apr}$ 2021 at www.hkmj.org
$\left(\mathrm{OR}_{\mathrm{adj}}=1.32 ; 95 \% \mathrm{CI}=1.02-3.28\right)$.

Conclusion: The temporary test centre successfully helped identify individuals with COVID-19 who exhibited mild disease symptoms. Healthcare providers should carefully consider the epidemiological and clinical characteristics of COVID-19 to arrange early testing to reduce community spread.

\begin{tabular}{l} 
Hong Kong Med J 2021;27:99-105 \\
\hline https://doi.org/10.12809/hkmj208909 \\
${ }^{1}$ WLH Leung *, MB, ChB, FHKAM (Family Medicine) \\
${ }^{2}$ ELM Yu, BSc (Stat \& Fin), MSc (Epi \& Biostat) \\
${ }^{3}$ SC Wong, MNurs \\
${ }^{4}$ M Leung, PhD \\
${ }^{5}$ LLY Lee, MB, BS (NSW), FHKAM (Emergency Medicine) \\
${ }^{6}$ KL Chung, MB, BS, FHKAM (Emergency Medicine) \\
${ }^{7}$ VCC Cheng, MB, BS, MD \\
${ }^{1}$ Department of Family Medicine and Primary Health Care, Kowloon West \\
Cluster, Hospital Authority, Hong Kong \\
${ }^{2}$ Clinical Research Centre, Princess Margaret Hospital, Hong Kong \\
${ }^{3}$ Infection Control Team, Queen Mary Hospital, Hong Kong West Cluster, \\
Hospital Authority, Hong Kong \\
${ }^{4}$ Central Nursing Department, Hospital Authority, Hong Kong \\
${ }^{5}$ Department of Accident and Emergency, Tin Shui Wai Hospital, Hong \\
Kong \\
${ }^{6}$ Quality \& Safety Division, Hospital Authority, Hong Kong \\
${ }^{7}$ Department of Microbiology, Queen Mary Hospital, Hong Kong \\
* Corresponding author: Ilh864@ha.org.hk \\
\end{tabular}

New knowledge added by this study

- A temporary test centre during the coronavirus disease 2019 (COVID-19) pandemic was effective for the identification of severe acute respiratory syndrome coronavirus 2 (SARS-CoV-2) infection among individuals who exhibited mild disease symptoms.

- At the temporary test centre at AsiaWorld-Expo, a greater proportion of infected individuals were aged 15 to 24 years $(46.5 \%)$, compared with the proportion $(26.7 \%)$ in a previously described age-matched population in Hong Kong, presumably because of the targeted testing strategy used at the centre.

- In our relatively healthy population of individuals with mild disease symptoms and epidemiological linkage to COVID-19, 6.84\% had positive test results.

Implications for clinical practice or policy

- In some individuals, COVID-19 causes mild initial symptoms despite its high infectivity; thus, there is a need for early identification of individuals with SARS-CoV-2 who exhibit mild symptoms.

- The temporary test centre was successful in identifying infected individuals in a large-scale, high-turnover setting, thereby reducing the testing burden in secondary and tertiary healthcare facilities.

- Gatekeeping healthcare providers should carefully consider the epidemiological and clinical manifestations of COVID-19 and be vigilant in arranging appropriate early testing to reduce community spread. 


\section{香港首間公營2019冠狀病毒病臨時檢測中心 的研究}

\author{
梁樂行、余洛汶、黃淑貞、梁明、李立業、鍾健禮、鄭智聰
}

引言：香港醫院管理局在2020年3月至4月期間，在赤鯤角亞洲國際博 覽館成立香港首間公營2019冠狀病毒病臨時檢測中心, 為高風險人士 進行冠狀病毒核酸檢測, 及早識別輕微病徵的確診者。本研究旨在探 討在臨時檢測中心營運期間接受檢測人士的特徵與檢測結果。

方法：本研究收集接受檢測人士的流行病學和臨床資料, 以分析鼻咽 和咽喉合併拭子核酸檢測呈陽性與陰性兩個組別就着流行病學與臨床 數據的相關性。

結果：在 1258 個檢測樣本中，86個樣本呈陽性（陽性比率6.84\%； $95 \%$ 置信區間 $=5.57 \%-8.37 \%$ ），當中 40 個陽性樣本（ $46.5 \%$ ) 屬 15 至 24歲組群，81個陽性樣本（94.2\%）屬外地抵港人士。86.0\%陽性患 者及 $96.3 \%$ 陰性人士表示帶有徵狀。嗅覺喪失（校正比值比 $=8.30$; 95\%置信區間 $=1.12-127.09$ ) 和發燒（校正比值比 $=1.32 ； 95 \%$ 置信區 間=1.02-3.28）在統計學上與陽性檢測結果呈相關。

結論：臨時檢測中心在香港第二波2019冠狀病毒病疫情期間發揮重要 作用, 及早發現帶有輕微病徵的 2019 冠狀病毒病病人。醫護人員應 細心考慮求診者的流行病學與臨床數據, 及早為懷疑個案安排病毒檢 測, 減低社區傳播的風險。

\section{Introduction}

Patients with coronavirus disease 2019 (COVID-19), including those with mild or no symptoms, may readily transmit the disease given the high personto-person infectivity in the latent period of COVID-19; this transmission could threaten public health. ${ }^{1}$ Severe acute respiratory syndrome coronavirus 2 (SARS-CoV-2), the causative virus of COVID-19, replicates efficiently in the upper respiratory tract and appears to cause delayed onset of symptoms; therefore, COVID-19 poses considerable challenges to the health system. ${ }^{2,3}$ Thus, there is a need to rapidly identify infected individuals who exhibit only mild symptoms. In March to April 2020, the Hospital Authority, Hong Kong, established a temporary test centre (TTC) at the AsiaWorld-Expo (AWE), which is within the Hong Kong International Airport complex on Lantau Island. The AWE TTC offered tests for individuals with mild symptoms among those arriving at the airport, as well as those engaged in home quarantine in Hong Kong, for the early detection of SARS-CoV-2 infection that could be managed by early isolation and intervention. ${ }^{4}$ Asymptomatic individuals were tested at a different facility within AWE operated by the Department of Health. This study reviewed the characteristics and outcomes of individuals who attended the AWE TTC for COVID-19 testing.

\section{Methods}

This retrospective cross-sectional study evaluated the characteristics and outcomes of individuals who attended the AWE TTC during its operation from 20 March 2020 to 19 April 2020. All individuals who attended the AWE TTC were included, with the exception of patients who were transferred out of the AWE TTC to accident and emergency departments before they could undergo COVID-19 testing. Infection control measures implemented at the AWE TTC were reported previously. ${ }^{5}$ Ethics approval was obtained from the Kowloon West Cluster Research Ethics Committee, Hospital Authority.

Clinical characteristics assessed in this study were fever, chills, cough, runny nose, sore throat, vomiting, diarrhoea, fatigue, myalgia, headache, anosmia, history of hypertension, history of diabetes mellitus, history of chronic respiratory disease, and history of malignancy. Epidemiological parameters assessed in this study were age, sex, district of residence, travel history, occupational exposure, contact history, and clustering history. These data were collected using a standard clinical assessment template by duty medical officers in the Clinical Management System of the Hospital Authority. The primary outcome was positive or negative SARS-CoV-2 test results, according to reverse transcription polymerase chain reaction analyses of pooled nasopharyngeal and throat swabs collected at the AWE TTC.

The positivity rate with $95 \%$ confidence interval (CI) was calculated. Demographic and clinical characteristics of individuals with positive and negative test results were compared using Pearson's Chi squared test, Fisher's exact test, or the MannWhitney $U$ test, as appropriate. Adjusted odds ratios with 95\% Wald CIs were derived using multivariable binary logistic regression to assess the associations of clinical characteristics with SARS-CoV-2 positive test results. Partially standardised beta coefficients were used to compare the strengths of associations between individual clinical characteristics and SARS-CoV-2 test results; a greater absolute value of the partially standardised beta coefficient was indicative of a stronger association. Ridge regression was performed to implement penalisation for management of the sparse data bias elicited by the low prevalences of some clinical characteristics. ${ }^{6,7}$ The tuning parameter $\lambda$ was identified as the optimal value that resulted in minimal error via 10 -fold cross-validation; as the tuning parameter $\lambda$ became larger, the estimated odds ratio decreased towards a value of 1 . Bootstrapping was used to construct 95\% CIs with 100 bootstrap replications. Statistical analyses were performed using $\mathrm{R}$ version 3.6 .1 with "glmnet" and "boot" packages. A P value of $<0.05$ was considered statistically significant.

\section{Results}

In total, 1286 individuals attended the AWE TTC for 
TABLE I. Demographic and clinical characteristics of attendees at the AsiaWorld-Expo temporary test centre $(n=1258)^{*}$

\begin{tabular}{|c|c|c|c|c|}
\hline & $\begin{array}{c}\text { All } \\
(n=1258)\end{array}$ & $\begin{array}{l}\text { Positive test result } \\
\qquad(\mathrm{n}=86)\end{array}$ & $\begin{array}{c}\text { Negative test } \\
\text { result } \\
(n=1172)\end{array}$ & $\mathrm{P}$ value \\
\hline \multicolumn{5}{|l|}{ Demographics } \\
\hline Male sex & $652(51.8 \%)$ & $46(53.5 \%)$ & $606(51.7 \%)$ & 0.750 \\
\hline Age, y & $27.3 \pm 11.8$ & $30.6 \pm 14.6$ & $27.1 \pm 11.6$ & 0.066 \\
\hline $0-14$ & $23(1.8 \%)$ & $2(2.3 \%)$ & $21(1.8 \%)$ & \\
\hline $15-24$ & $740(58.8 \%)$ & $40(46.5 \%)$ & 700 (59.7\%) & \\
\hline $25-44$ & $343(27.3 \%)$ & $26(30.2 \%)$ & 317 (27.0\%) & \\
\hline $45-64$ & $147(11.7 \%)$ & $17(19.8 \%)$ & $130(11.1 \%)$ & \\
\hline 65 or above & $5(0.4 \%)$ & $1(1.2 \%)$ & $4(0.3 \%)$ & \\
\hline Non-Chinese ethnicity & $127(10.1 \%)$ & $13(15.1 \%)$ & $114(9.7 \%)$ & 0.109 \\
\hline Region of residence & & & & 0.140 \\
\hline Hong Kong Island & $273(21.7 \%)$ & $27(31.4 \%)$ & $246(21.0 \%)$ & \\
\hline Kowloon & $369(29.3 \%)$ & $22(25.6 \%)$ & 347 (29.6\%) & \\
\hline New Territories & $607(48.3 \%)$ & $36(41.9 \%)$ & 571 (48.7\%) & \\
\hline Others & $9(0.7 \%)$ & $1(1.2 \%)$ & $8(0.7 \%)$ & \\
\hline History of travel & $1190(94.6 \%)$ & $81(94.2 \%)$ & 1109 (94.6\%) & 0.804 \\
\hline Occupation & $23(1.8 \%)$ & $3(3.5 \%)$ & $20(1.7 \%)$ & 0.204 \\
\hline Cluster or contact history & $153(12.2 \%)$ & $28(32.6 \%)$ & $125(10.7 \%)$ & $<0.001$ \\
\hline \multicolumn{5}{|l|}{ Clinical characteristics } \\
\hline Symptomatic & 1203 (95.6\%) & $74(86.0 \%)$ & 1129 (96.3\%) & $<0.001$ \\
\hline Ever febrile & $224(17.8 \%)$ & $32(37.2 \%)$ & $192(16.4 \%)$ & $<0.001$ \\
\hline Documented fever & $110(8.7 \%)$ & $8(9.3 \%)$ & $102(8.7 \%)$ & \\
\hline Reported fever & $169(13.4 \%)$ & $29(33.7 \%)$ & 140 (11.9\%) & \\
\hline Chills & $86(6.8 \%)$ & $11(12.8 \%)$ & $75(6.4 \%)$ & 0.023 \\
\hline Cough & $765(60.8 \%)$ & $47(54.7 \%)$ & $718(61.3 \%)$ & 0.225 \\
\hline Runny nose & 435 (34.6\%) & $23(26.7 \%)$ & $412(35.2 \%)$ & 0.114 \\
\hline Sore throat & $590(46.9 \%)$ & $27(31.4 \%)$ & $563(48.0 \%)$ & 0.003 \\
\hline Vomiting & $13(1.0 \%)$ & $1(1.2 \%)$ & $12(1.0 \%)$ & 0.604 \\
\hline Diarrhoea & $147(11.7 \%)$ & $11(12.8 \%)$ & $136(11.6 \%)$ & 0.741 \\
\hline Fatigue & $106(8.4 \%)$ & $19(22.1 \%)$ & $87(7.4 \%)$ & $<0.001$ \\
\hline Myalgia & $77(6.1 \%)$ & $8(9.3 \%)$ & $69(5.9 \%)$ & 0.202 \\
\hline Headache & $145(11.5 \%)$ & $14(16.3 \%)$ & $131(11.2 \%)$ & 0.153 \\
\hline Anosmia & $22(1.7 \%)$ & $19(22.1 \%)$ & $3(0.3 \%)$ & $<0.001$ \\
\hline \multicolumn{5}{|l|}{ Chronic health conditions } \\
\hline Hypertension & $14(1.1 \%)$ & $3(3.5 \%)$ & $11(0.9 \%)$ & 0.065 \\
\hline Diabetes mellitus & $11(0.9 \%)$ & $1(1.2 \%)$ & $10(0.9 \%)$ & 0.543 \\
\hline Chronic respiratory disease & $10(0.8 \%)$ & $2(2.3 \%)$ & $8(0.7 \%)$ & 0.145 \\
\hline Malignancy & $5(0.4 \%)$ & $1(1.2 \%)$ & $4(0.3 \%)$ & 0.299 \\
\hline
\end{tabular}

* Data are shown as No. (\%) or mean \pm standard deviation

+ Pearson's Chi squared test, Fisher's exact test, or the Mann-Whitney U test

COVID-19 testing (Table 1). Of these 1286 attendees, because of severe symptoms requiring investigation 1258 were included in the analysis after the exclusion or therapy beyond the capacity of the AWE TTC. of three attendees with important missing data These severe symptoms included shortness of breath and 25 attendees who were immediately referred $(n=8)$; high fever $(n=5)$; chest discomfort $(n=5)$; to regional accident and emergency departments acute gastrointestinal symptoms $(n=4)$; and acute 
TABLE 2. Travel histories of attendees at the AsiaWorld-Expo temporary test centre*

\begin{tabular}{|c|c|c|c|c|}
\hline \multirow[t]{2}{*}{ Origin } & \multicolumn{2}{|c|}{ Primary } & \multicolumn{2}{|c|}{ Secondary } \\
\hline & $\begin{array}{c}\text { Total } \\
(n=1258)\end{array}$ & $\begin{array}{l}\text { Positive } \\
\text { No. (\%) }\end{array}$ & $\begin{array}{c}\text { Total } \\
(\mathrm{n}=258)\end{array}$ & $\begin{array}{l}\text { Positive } \\
\text { No. (\%) }\end{array}$ \\
\hline $\mathrm{Nil}$ & 68 & $5(7.4 \%)$ & - & - \\
\hline United Kingdom & 652 & 54 (8.3\%) & 16 & $6(37.5 \%)$ \\
\hline United States & 141 & $6(4.3 \%)$ & 3 & $1(33.3 \%)$ \\
\hline Peru & 6 & 5 (83.3\%) & 1 & $1(100 \%)$ \\
\hline France & 19 & 3 (15.8\%) & 6 & 0 \\
\hline Malaysia & 14 & 2 (14.3\%) & 10 & 0 \\
\hline Spain & 10 & $2(20 \%)$ & 3 & 0 \\
\hline Australia & 57 & $1(1.8 \%)$ & 0 & - \\
\hline Canada & 51 & $1(2.0 \%)$ & 8 & $1(12.5 \%)$ \\
\hline China & 44 & $1(2.3 \%)$ & 1 & 0 \\
\hline Indonesia & 36 & $1(2.8 \%)$ & 0 & - \\
\hline Netherland & 9 & $1(11.1 \%)$ & 8 & $1(12.5 \%)$ \\
\hline Brazil & 4 & $1(25 \%)$ & 0 & - \\
\hline Macau & 1 & $1(100 \%)$ & 0 & - \\
\hline Nigeria & 1 & $1(100 \%)$ & 0 & - \\
\hline Argentina & 1 & $1(100 \%)$ & 0 & - \\
\hline Germany & 19 & 0 & 18 & $1(5.6 \%)$ \\
\hline Singapore & 19 & 0 & 17 & $1(5.9 \%)$ \\
\hline Japan & 16 & 0 & 9 & $1(11.1 \%)$ \\
\hline Thailand & 13 & 0 & 12 & $1(8.3 \%)$ \\
\hline Belgium & 1 & 0 & 5 & $1(20 \%)$ \\
\hline United Arab Emirates & 0 & 0 & 50 & $4(8 \%)$ \\
\hline Qatar & 0 & 0 & 30 & $2(6.7 \%)$ \\
\hline Chile & 0 & 0 & 2 & $1(50 \%)$ \\
\hline Philippines & 14 & 0 & 0 & - \\
\hline New Zealand & 8 & 0 & 2 & 0 \\
\hline Switzerland & 5 & 0 & 9 & 0 \\
\hline Finland & 4 & 0 & 5 & 0 \\
\hline Sweden & 4 & 0 & 1 & 0 \\
\hline Vietnam & 4 & 0 & 1 & 0 \\
\hline Taiwan & 3 & 0 & 5 & 0 \\
\hline Czech Republic & 3 & 0 & 2 & 0 \\
\hline Mexico & 3 & 0 & 2 & 0 \\
\hline Nepal & 3 & 0 & 0 & - \\
\hline Turkey & 2 & 0 & 4 & 0 \\
\hline Denmark & 2 & 0 & 1 & 0 \\
\hline Hungary & 2 & 0 & 0 & - \\
\hline India & 2 & 0 & 0 & - \\
\hline Morocco & 2 & 0 & 0 & - \\
\hline Austria & 1 & 0 & 5 & 0 \\
\hline Portugal & 1 & 0 & 5 & 0 \\
\hline Norway & 1 & 0 & 3 & 0 \\
\hline Cambodia & 1 & 0 & 1 & 0 \\
\hline Africa & 1 & 0 & 0 & - \\
\hline Bangladesh & 1 & 0 & 0 & - \\
\hline Greece & 1 & 0 & 0 & - \\
\hline Holland & 1 & 0 & 0 & - \\
\hline Israel & 1 & 0 & 0 & - \\
\hline Kazakhstan & 1 & 0 & 0 & - \\
\hline South Korea & 1 & 0 & 0 & - \\
\hline Myanmar & 1 & 0 & 0 & - \\
\hline Russia & 1 & 0 & 0 & - \\
\hline South Africa & 1 & 0 & 0 & - \\
\hline Tanzania & 1 & 0 & 0 & - \\
\hline Iceland & 0 & - & 4 & 0 \\
\hline Italy & 0 & - & 3 & 0 \\
\hline Albania & 0 & - & 1 & 0 \\
\hline Luxembourg & 0 & - & 1 & 0 \\
\hline Nicaragua & 0 & - & 1 & 0 \\
\hline Poland & 0 & - & 1 & 0 \\
\hline Portugal & 0 & - & 1 & 0 \\
\hline Slovenia & 0 & - & 1 & 0 \\
\hline
\end{tabular}

* Data are shown as No. (\%) ear, nose, throat symptoms $(n=3)$. Finally, 1242 individuals were involved in the analysis because 16 individuals attended the AWE TTC twice due to ongoing or changing symptoms; the remaining 1226 individuals attended the AWE TTC only once for testing. Among the 1258 included tests, five showed indeterminate results during the first sampling, while subsequent re-tests revealed negative results; thus, there were 86 positive SARS-CoV-2 results with a positivity rate of $6.84 \%$ (95\% CI=5.57\%-8.37\%). During the study period, the maximum number of attendees $(n=79)$ was recorded on 30 March 2020 and the highest daily number of positive test results $(\mathrm{n}=8)$ was recorded on 6 April 2020. Attendees with positive test results were all admitted to public hospitals through central coordination for further clinical assessment and treatment.

Most attendees were aged 15 to 24 years (740/1258, 58.8\%). Furthermore, most attendees $(\mathrm{n}=1190,94.6 \%)$ were incoming travellers from the United Kingdom, the United States, Canada, Australia, and other parts of the world (Table 2). A history of travel to the United Kingdom was significantly associated with positive test results (69.8\% [60/86] of positive test results vs $51.9 \%$ [608/1172] of negative test results; $\mathrm{P}=0.001$ ). Cluster or contact history was reported by $32.6 \%$ of attendees with positive test results and $10.7 \%$ of attendees with negative test results $(\mathrm{P}<0.001)$. The most frequently reported symptoms among all attendees were cough $(60.8 \%)$, sore throat $(46.9 \%)$, and runny nose $(34.6 \%)$. Symptoms were reported by $86.0 \%$ and $96.3 \%$ of individuals with positive and negative test results, respectively.

The clinical characteristics most strongly associated with a positive test result were anosmia (ridge regression adjusted odds ratio $\left[\mathrm{OR}_{\mathrm{adj}}\right]=8.30$; $95 \% \mathrm{CI}=1.12-127.09)$ and fever $\left(\mathrm{OR}_{\mathrm{adj}}=1.32\right.$; 95\% CI=1.02-3.28) [Table 3]. Sore throat was significantly associated with a negative test result $\left(\mathrm{OR}_{\mathrm{adj}}=0.86 ; 95 \% \mathrm{CI}=0.36-0.99\right)$. Other characteristics (ie, cough, runny nose, fatigue, headache, myalgia, vomiting, chills, and diarrhoea) did not show significant associations with positive or negative test results, according to ridge regression analysis.

\section{Discussion}

To the best of our knowledge, this is the first study in Hong Kong to explore the clinical characteristics of attendees at a public TTC established by the Hospital Authority in response to a worldwide pandemic. Early identification and early containment have been critical strategies adopted by the Centre for Health Protection, Hong Kong to address the pandemic. Locally, the first imported case in an individual with a history of travel outside mainland China was reported on 4 March 2020. This was followed by a large number 
TABLE 3. Associations of clinical characteristics of attendees at the AsiaWorld-Expo temporary test centre with SARS-CoV-2positive test results: multivariable regression analyses

\begin{tabular}{|c|c|c|c|c|}
\hline & \multicolumn{3}{|c|}{ Logistic regression } & \multirow{2}{*}{$\begin{array}{l}\text { Ridge regression } \\
\text { Adjusted odds ratio } \\
\text { (95\% bootstrap } \mathrm{Cl} \text { ) }\end{array}$} \\
\hline & $\begin{array}{l}\text { Absolute partially } \\
\text { standardised } \\
\text { coefficient }\end{array}$ & $\begin{array}{l}\text { Adjusted odds ratio } \\
\text { (95\% Wald Cl) }\end{array}$ & $P$ value & \\
\hline Anosmia & 0.626 & 118.39 (32.47-431.66) & $<0.001$ & $8.30(1.12-127.09)$ \\
\hline Sore throat & 0.429 & $0.42(0.52-0.73)$ & 0.002 & $0.86(0.36-0.99)$ \\
\hline Ever febrile & 0.409 & $2.91(1.69-5.00)$ & $<0.001$ & $1.32(1.02-3.28)$ \\
\hline Fatigue & 0.357 & $3.62(1.67-7.84)$ & 0.001 & $1.38(0.95-5.09)$ \\
\hline Runny nose & 0.314 & $0.52(0.29-0.93)$ & 0.028 & $0.91(0.42-1.00)$ \\
\hline Cough & 0.178 & $0.69(0.42-1.15)$ & 0.159 & $0.94(0.53-1.15)$ \\
\hline Headache & 0.069 & $0.81(0.37-1.78)$ & 0.594 & $1.05(0.49-1.42)$ \\
\hline Myalgia & 0.061 & $0.77(0.28-2.15)$ & 0.694 & $1.05(0.37-1.57)$ \\
\hline Vomiting & 0.039 & $1.47(0.17-12.54)$ & 0.723 & $1.04(0.22-7.56)$ \\
\hline Chills & 0.006 & $0.98(0.40-2.36)$ & 0.958 & $1.14(0.61-2.14)$ \\
\hline Diarrhoea & 0.005 & $1.02(0.46-2.23)$ & 0.969 & $1.00(0.57-1.55)$ \\
\hline
\end{tabular}

Abbreviations: $95 \% \mathrm{Cl}=95 \%$ confidence interval; SARS-CoV-2 = severe acute respiratory syndrome coronavirus 2

of imported cases involving returning travellers, including 245 students from the United Kingdom and the United States who had positive test results; the maximum number of cases $(n=65)$ was reported on 27 March $2020 .^{8}$ The establishment of a TTC was a crucial public health intervention to address the influx of returning overseas travellers during the worldwide spread of COVID-19 beginning in March 2020. Given the potential transmission of COVID-19 among individuals with relatively mild clinical symptoms, early identification of SARS-CoV-2 infection by reverse transcription polymerase chain reaction testing is crucial for reducing disease spread. ${ }^{9}$ The AWE TTC was equipped with extensive testing capacity for the target population of individuals with mild disease symptoms.

Among AWE TTC attendees, the majority of positive test results were recorded in young individuals (aged 15-24 years; 40 of 86 cases), who comprised $46.5 \%$ of total attendees with positive test results. Notably, this proportion was greater than the proportion reported by the Centre for Health Protection concerning individuals in the same age-group (289 of 1084 cases; $26.7 \%$ ) among all COVID-19 cases in Hong Kong during the study period. This is potentially attributable to the targeted testing strategy that focused on incoming overseas students, which was implemented after the Hong Kong Government announced compulsory testing and quarantine for all arriving travellers beginning on 19 March $2020 .{ }^{10}$ We previously reported that most individuals could be tested on-site; moreover, the AWE TTC fulfilled its gatekeeping role by reducing the number of hospital admissions by
36 patients per day during its 31 days of operation. ${ }^{5}$ Primary care providers and emergency physicians have performed important gatekeeping roles in the early identification of individuals with COVID-19. However, a local Family Physician survey revealed that this gatekeeping task is challenging because of the non-specific and mild disease manifestations in many individuals with SARS-CoV-2 infections. ${ }^{11}$ In Hong Kong, among 1084 confirmed cases reported between January 2020 and May 2020, symptoms were reported by 859 (79.2\%) affected patients. The five most common symptoms reported by Hong Kong patients with COVID-19 included cough $(436,50.8 \%)$, fever $(428,49.8 \%)$, sore throat $(174,20.3 \%)$, headache $(98,11.4 \%)$, and runny nose (97, 11.3\%). The remaining 225 patients (20.8\%) were asymptomatic. ${ }^{8}$ An early study of 41 patients in Wuhan, published in January 2020, revealed that the most common symptoms at onset of illness were fever (98\%), cough $(76 \%)$, and myalgia or fatigue $(44 \%){ }^{12}$ A multicentre study in Shanghai reported that the most common symptoms among 1004 patients with positive test results were fever (84\%), cough (62\%), and fatigue (25\%). ${ }^{13}$ Our study reviewed the clinical characteristics and outcomes of relatively healthy individuals in Hong Kong whose demographic characteristics were similar to those of the general practice population; we found that the three most common symptoms among infected individuals were cough, fever, and sore throat (Table 1), consistent with the findings in a local study by the Centre for Health Protection. ${ }^{8}$ In addition to the usual upper respiratory tract symptoms, our results showed that fever and anosmia were strongly associated 
with positive test results. These findings provide important guidance for gatekeeping physicians to carefully consider symptoms such as anosmia (a relatively uncommon symptom in primary care consultations), which was present in $22.1 \%$ of our attendees with positive test results and only $0.3 \%$ of attendees with negative test results. Evidence of such symptoms should alert clinicians to the potential presence of COVID-19. A study performed in South Korea revealed that acute olfactory disturbance was present in $15.3 \%$ of patients (488/3191) in the early stage of COVID-19. Its prevalence was significantly more common among female patients and younger individuals $\left(\mathrm{P}=0.01\right.$ and $\mathrm{P}<0.001$, respectively). ${ }^{14} \mathrm{~A}$ study performed in the Netherlands showed that anosmia was present in $47 \%$ of individuals with positive test results and was strongly associated with SARS-CoV-2 positivity (odds ratio=23.0; $95 \% \mathrm{CI}=8.2 \%-64.8 \%){ }^{15}$ In our study, the $\mathrm{OR}_{\text {adj }}$ for anosmia was 8.30 (95\% CI=1.12-127.09), indicating a strong association between anosmia and a positive test result. However, this result should be interpreted cautiously, considering the potential for over- or under-reporting of the symptom at a cross-sectional encounter, the co-existence of other conditions that may lead to olfactory disturbance, and the timing of illness presentation. The probability of identifying an infected individual depends on the incubation period and the proportion of individuals with subclinical disease. ${ }^{16}$ Symptoms alone might not be reliable for diagnosis. Early testing is critical for the early identification of both symptomatic and asymptomatic individuals. This approach has been particularly essential with worsening disease spread, which has required stricter infection control measures since July $2020.17,18$

Of the 1286 AWE TTC attendees, 25 (1.94\%) with severe symptoms were immediately transferred to the accident and emergency departments; these attendees did not undergo testing at the AWE TTC. The inclusion and exclusion criteria used in this TTC could be useful for planning and implementation efforts (in terms of referral criteria) if similar centres must be established in future emergency circumstances. Notably, this type of centre is considered safe and efficient for screening to reduce community disease spread ${ }^{19}$ and could be more readily implemented to manage an infectious disease, compared with vaccination and effective antiviral therapy. ${ }^{20}$

The strengths of this study were its large sample size and centralised setting that allowed coverage of the entire Hong Kong population (regardless of residential location) with elevated COVID-19 risk, including those arriving at the airport and those under home quarantine; all AWE TTC attendees exhibited mild disease symptoms similar to those of potentially infected individuals encountered in primary care settings. The limitations of this study included its retrospective data collection based on electronic health records. Investigators could not verify the reported conditions of the AWE TTC attendees or recover any important missing data. Nevertheless, all AWE TTC attendees were assessed by physicians with a standard questionnaire for documentation of demographics and symptoms; they were also tested by reverse transcription polymerase chain reaction analyses of standard pooled nasopharyngeal and throat swabs, which provided clear positive and negative results that facilitated data analysis. Another limitation of the study involved its cross-sectional study design. The epidemiological information and clinical symptoms collected during patient assessment at the AWE TTC might not be identical to those of post-admission situations because the patients' conditions might have changed in a manner dependent on the timing of presentation. For example, a study of 1099 patients in China found that fever was present in $43.8 \%$ of patients on admission, but was present in $88.7 \%$ of patients during hospitalisation. ${ }^{21}$ Importantly, the present study could not offer predictive value or relative risk projection on the basis of its epidemiological and clinical findings. Further studies with a longitudinal design may provide useful epidemiological and clinical insights.

\section{Conclusion}

In some individuals, COVID-19 causes mild initial symptoms despite its high infectivity; thus, there is a need for early identification of individuals with SARS-CoV-2 infection who exhibit mild symptoms. The establishment of a TTC was successful in identifying infected individuals in a large-scale, high-turnover setting, thereby reducing the testing burden in secondary and tertiary healthcare facilities. Gatekeeping healthcare providers should carefully consider the epidemiological and clinical manifestations of COVID-19 and be vigilant in arranging appropriate early testing to reduce community spread.

\section{Author contributions}

Concept or design: WLH Leung, ELM Yu.

Acquisition of data: WLH Leung.

Analysis or interpretation of data: WLH Leung, ELM Yu.

Drafting of the manuscript: WLH Leung.

Critical revision of the manuscript for important intellectual content: All authors.

All authors had full access to the data, contributed to the study, approved the final version for publication, and take responsibility for its accuracy and integrity.

\section{Conflicts of interest}

All authors have disclosed no conflicts of interest. 


\section{Acknowledgement}

The authors acknowledge all workers involved in the setup and operation of the temporary test centre at AsiaWorld-Expo, Hong Kong.

\section{Funding/support}

This research received no specific grant from any funding agency in the public, commercial, or not-for-profit sectors.

\section{Ethics approval}

This study was approved by the Kowloon West Cluster Research Ethics Committee, Hospital Authority [Ref KW/EX20-085(148-09)]. The Ethics Committee waived the need for patient consent for this retrospective study.

\section{References}

1. Bai Y, Yao L, Wei T, et al. Presumed asymptomatic carrier transmission of COVID-19. JAMA 2020;323:1406-7.

2. Heymann DL, Shindo N, WHO Scientific and Technical Advisory Group for Infectious Hazards. COVID-19: what is next for public health? Lancet 2020;395:542-5.

3. Chan JF, Yuan S, Kok KH, et al. A familial cluster of pneumonia associated with the 2019 novel coronavirus indicating person-to-person transmission: a study of a family cluster. Lancet 2020;395:514-23.

4. Hong Kong SAR Government. Temporary test centres speed up tests for people upon arrival. Available from: https://www.info.gov.hk/gia/general/202003/19/ P2020031900664.htm. Accessed 11 Jul 2020.

5. Wong SC, Leung M, Lee LL, Chung KL, Cheng VC. Infection control challenge in setting up a temporary test centre at Hong Kong International Airport for rapid diagnosis of COVID-19 due to SARS-CoV-2. J Hosp Infect 2020;105:571-3.

6. Greenland S, Mansournia MA, Altman DG. Sparse data bias: a problem hiding in plain sight. BMJ 2016;352:11981.

7. Doerken S, Avalos M, Lagarde E, Schumacher M. Penalized logistic regression with low prevalence exposures beyond high dimensional settings. PloS One 2019;14:e217057.

8. Lam HY, Lam TS, Wong $\mathrm{CH}$, et al. The epidemiology of COVID-19 cases and the successful containment strategy in Hong Kong-January to May 2020. Int J Infect Dis 2020;98:51-8.

9. To KK, Yuen KY. Responding to COVID-19 in Hong Kong.
Hong Kong Med J 2020;26:164-6.

10. Hong Kong SAR Government. Compulsory quarantine law gazetted. Available from: https://www.news.gov.hk/eng/20 20/03/20200318/20200318_211807_723.html. Accessed 11 Jul 2020.

11. Yu EY, Leung WL, Wong SY, Liu KS, Wan EY, HKCFP Executive and Research Committee. How are family doctors serving the Hong Kong community during the COVID-19 outbreak? A survey of HKCFP members. Hong Kong Med J 2020;26:176-83.

12. Huang C, Wang Y, Li X, et al. Clinical features of patients infected with 2019 novel coronavirus in Wuhan, China. Lancet 2020;395:497-506.

13. Mao B, Liu Y, Chai $\mathrm{YH}$, et al. Assessing risk factors for SARS-CoV-2 infection in patients presenting with symptoms in Shanghai, China: a multicentre, observational cohort study. Lancet Digit Health 2020;2:e323-30.

14. Lee Y, Min P, Lee S, Kim SW. Prevalence and duration of acute loss of smell or taste in COVID-19 patients. J Korean Med Sci 2020;35:e174.

15. Tostmann A, Bradley J, Bousema T, et al. Strong associations and moderate predictive value of early symptoms for SARS-CoV-2 test positivity among healthcare workers, the Netherlands, March 2020. Euro Surveill 2020;25:2000508.

16. Gostic K, Gomez AC, Mummah RO, Kucharski AJ, Lloyd-Smith JO. Estimated effectiveness of symptom and risk screening to prevent the spread of COVID-19. Elife 2020;9:e55570.

17. Hong Kong SAR Government. Social distancing rules to be tightened. Available from: https://www.news.gov.hk/eng/2 020/07/20200709/20200709_175812_722.html. Accessed $11 \mathrm{Jul} 2020$

18. Hong Kong SAR Government. Government further tightens social distancing measures. Available from: https://www. info.gov.hk/gia/general/202007/27/P2020072700650.htm. Accessed 27 Jul 2020.

19. Kwon KT, Ko JH, Shin H, Sung M, Kim JY. Drive-through screening center for COVID-19: a safe and efficient screening system against massive community outbreak. J Korean Med Sci 2020;35:e123.

20. Peto J. Covid-19 mass testing facilities could end the epidemic rapidly. BMJ 2020;368:m1163.

21. Guan WJ, Ni ZY, Hu Y, et al. Clinical characteristics of coronavirus disease 2019 in China. N Engl J Med 2020;382:1708-20. 